\title{
2009 Influenza A (H1N1) in Panama: a disease affecting children with a benign course
}

\author{
Javier Nieto-Guevara, Néstor Sosa, Mariana García, Alex Martínez, \\ Marlene Castillo
}

Instituto Conmemorativo Gorgas de Estudios de la Salud, Panama

\begin{abstract}
Introduction: Pandemic Influenza A (H1N1) was identified as the major febrile respiratory illness worldwide during the year 2009. We present a report of its clinical and epidemiological characteristics in children and adults in Panama.

Methodology: A descriptive study from the database of the Gorgas Memorial Institute is presented. We included patients with severe acute respiratory infection in whom a nasopharyngeal swab was positive by real-time RT-PCR for 2009 Influenza A (H1N1) pandemic virus and negative for seasonal influenza A H1 and $\mathrm{H} 3$.

Results: From 26 April 2009 to 11 January 2010, confirmed cases of pandemic 2009 Influenza A (H1N1) reached 806. The overall incident rate was 23.35 cases of pandemic influenza per 100,000 habitants, with the highest incidence found in the age group between 10 to 14 years of age (58.67 cases per 100,000 habitants). The median age for the cases was 13 years (ages ranging from one day to 88 years) and $71 \%$ were from the Panama City Metropolitan Area. The male/female ratio was 1:1 and 90\% were managed as out-patients. An influenza-like syndrome was the presenting diagnosis in $99 \%$ of the cases. Fever and cough were the most frequent symptoms reported in all age groups. The case fatality rate was 0.3 cases per 100,000 habitants.

Conclusion: The 2009 Influenza A (H1N1) outbreak affected mainly the pediatric population, had a low case fatality rate, and was the predominant virus circulating in Panama during the 2009/2010 flu season.
\end{abstract}

Key words: epidemiology; pediatric; 2009 Influenza A (H1N1); Panama

J Infect Dev Ctries 2011; 5(9):664-668.

(Received 13 August 2010 - Accepted 04 July 2011)

Copyright $\odot 2011$ Nieto-Guevara et al. This is an open-access article distributed under the Creative Commons Attribution License, which permits unrestricted use, distribution, and reproduction in any medium, provided the original work is properly cited.

\section{Introduction}

The 2009 Influenza A (H1N1) pandemic virus has been identified as the cause of febrile respiratory infection in the United States (US) and worldwide $[1,2]$. In the US, the majority of the confirmed cases presented a self-limited uncomplicated febrile illness with similar symptoms to those of seasonal influenza, specifically cough, sore throat, rhinorrea, headache and myalgia). Nevertheless, pneumonia and respiratory failure have been described as determining factors for death, primarily in subjects with predisposing conditions [3] .

The Gorgas Memorial Institute (GMI) is the national reference laboratory of the Republic of Panama and has performed influenza surveillance since 1976. During the 2009 influenza pandemic, GMI was the only local laboratory to confirm the diagnosis of 2009 Influenza A (H1N1) pandemic virus using real-time RT-PCR [4] and viral culture [5]. The GMI was the first National Influenza Center (NIC) in the Central American region to be certified by the World Health Organization and since 2007 it has locally performed the routine diagnosis of seasonal influenza using molecular tests designed and approved by the Centers of Disease Control (CDC) in Atlanta, Georgia, USA [4], without the need to send the samples for initial testing. This fact permitted us to establish the diagnosis of 2009 Influenza A (H1N1) pandemic virus in a large number of cases in an expedited form.

We present a description of the number of cases and epidemiological characteristics of the subjects with 2009 Influenza A (H1N1) pandemic virus in Panama.

\section{Methodology}

Patient cohort description

This is a descriptive study based on the analysis of the database of the GMI. All subjects with acute respiratory infection whose nasopharyngeal swab was positive by real-time RT-PCR for 2009 Influenza A (H1N1) pandemic virus and negative for seasonal 
Table 1. Primer and probe sets

\begin{tabular}{|c|c|}
\hline $\begin{array}{l}\text { Primers } \\
\text { and Probes }\end{array}$ & Sequence $\left(5^{\prime} \rightarrow 3^{\prime}\right)$ \\
\hline Inf A Forward & AC CRA TCC TGT CAC CTC TGA C \\
\hline Inf A Reverse & AGG GCA TTY TGG ACA AAK CGT CTA \\
\hline Inf A Probe ${ }^{1}$ & TGC AGT CCT CGC TCA CTG GGC ACG \\
\hline SW Inf A Forward & GCA CGG TCA GCA CTT ATY CTR AG \\
\hline SW Inf A Reverse & GTG RGC TGG GTT TTC ATT TGG TC \\
\hline SW Inf A Probe ${ }^{2}$ & $\begin{array}{l}\text { CYA CTG CAA GCC CA"T" ACA CAC AAG } \\
\text { CAG GCA }\end{array}$ \\
\hline SW H1 Forward & GTG CTA TAA ACA CCA GCC TYC CA \\
\hline SW H1 Reverse & CGG GAT ATT CCT TAA TCC TGT RGC \\
\hline SW H1 Probe ${ }^{2}$ & $\begin{array}{l}\text { CA GAA TAT ACA “T”CC RGT CAC AAT } \\
\text { TGG ARA A }\end{array}$ \\
\hline RnaseP Forward & AGA TTT GGA CCT GCG AGC G \\
\hline RnaseP Reverse & GAG CGG CTG TCT CCA CAA GT \\
\hline RnaseP Probe $^{1}$ & TTC TGA CCT GAA GGC TCT GCG CG \\
\hline \multicolumn{2}{|c|}{$\begin{array}{l}1 \text { TaqMan® probes are labeled at the 5'-end with the reporter molecule 6-carboxyfluorescein } \\
\text { (FAM) and with the quencher, Blackhole Quencher } 1 \text { (BHQ1) (Biosearch Technologies, Inc., } \\
\text { Novato, CA) at the } 3 \text { '-end. } \\
2 \text { Taqman® probes are labeled at the 5'-end with the reporter molecule 6-carboxyfluorescein } \\
\text { (FAM) and quenched internally at a modified "T" residue with BHQ1, with a modified 3'- } \\
\text { end to prevent probe extension by Taq polymerase. } \\
\text { Note: primer/probe sets may undergo periodic modification as information about current } \\
\text { circulating viruses is known. }\end{array}$} \\
\hline
\end{tabular}

influenza A H1 and H3 between 26 April 2009 to 11 January 2010 were included in the study.

\section{Sample collection}

Samples sent to us came with clinical and demographic information completed by a referring physician and this information was later entered into the database.

\section{PCR methods}

The diagnosis of influenza A was conducted following the standard protocols recommended by the CDC [4]. First, the RNA was extracted using a commercial kit (QIAamp Viral RNA Mini Kit 250, Qiagen, Basel, Switzerland). Samples were screened with real-time RT-PCR using various algorithms starting with generic primers and probes (Table 1) targeted to a common matrix gene for influenza A with proper sample control RNaseP, which serves as an internal positive control for human nucleic acid. Once a positive Influenza A sample was obtained we proceeded to subtype with primers and probes directed at targets in the haemagglutinin gene that are specific for H1, H3, pandemic (H1N1) 2009, H5, etc. When positive influenza samples did not type as seasonal influenza $\mathrm{H} 1$ or $\mathrm{H} 3$ they became the first suspicious samples for the influenza A H1N1/09 pandemic virus. With this new virus the CDC quickly developed and posted genetic sequences on the web and sent the NICs the new primers and probes with protocols specific for 2009 Influenza A (H1N1) pandemic virus. They were tested in our laboratory using the one-step probe RT-PCR (Invitrogen SuperScrip III Platinum One-Step Quantitative Kit, Carlsbad, CA) in a 96-well format thermocycler system such as an Applied Biosystems real-time PCR 7300 (Foster City, CA) to confirm the presence of the 2009 Influenza A (H1N1) pandemic virus in Panama.

\section{Cell culture}

Nasal swab samples from patients with confirmed 2009 Influenza A (H1N1) pandemic virus diagnosis by real-time RT-PCR were used for viral isolation in a trypsinised cell line such as MadinDarby canine kidney (MDCK) [5] to provide a 
Table 2. General characteristic for all subjects

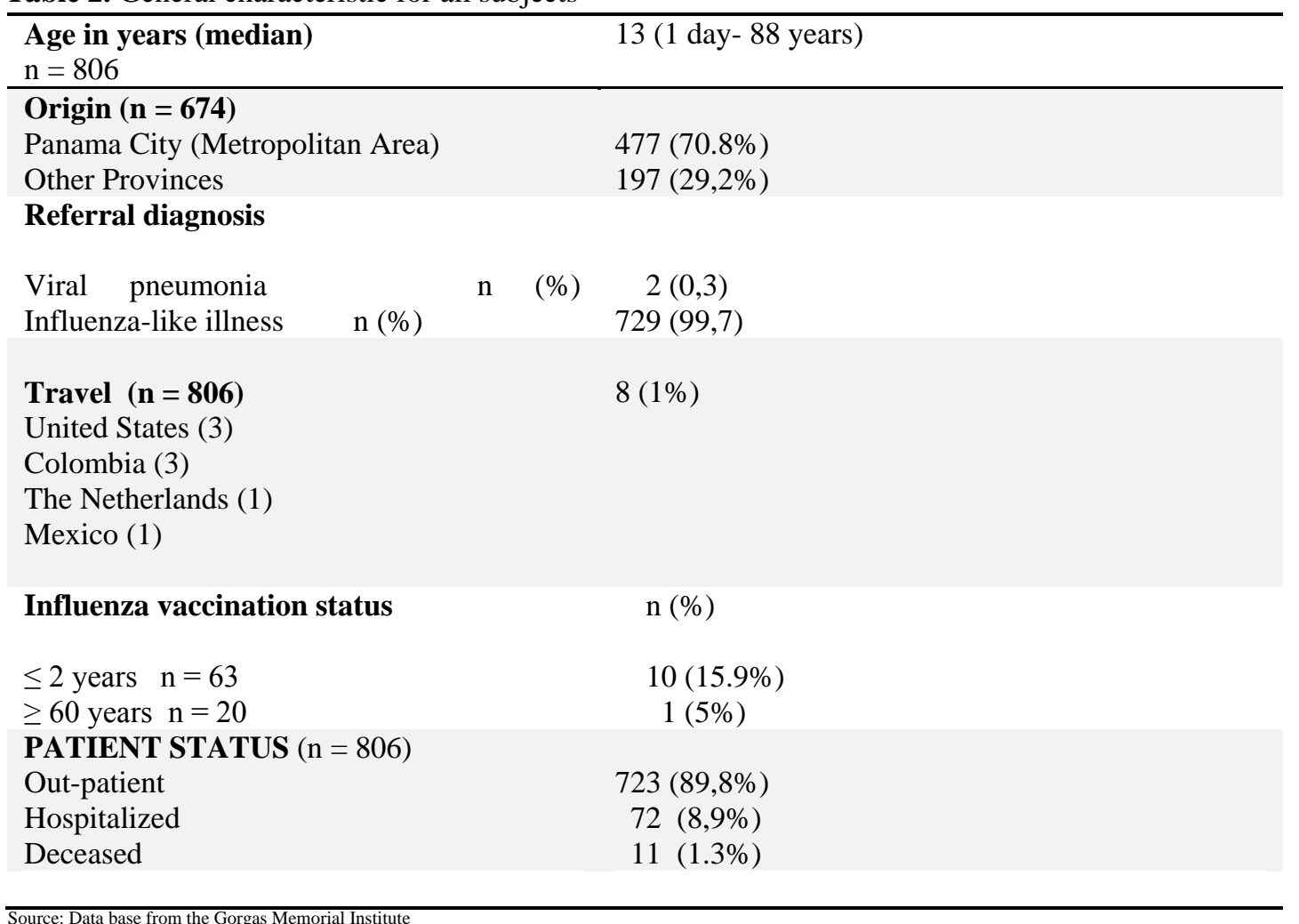

definitive diagnosis of influenza infection. Influenza virus growth is suggested by observation of typical cytopathic effect at two to three days. Confirmation is usually achieved by immunofluorescence using influenza type or subtype-specific monoclonal antibodies or by nucleic acid testing.

Cell culture provides virus for the more detailed antigenic analysis needed for strain identification and to assist vaccine selection, as well as the potential capacity to detect new influenza types that may be missed by other methods.

\section{Statistics}

The age groups were selected according to what is established by the General Comptroller office of the Republic of Panama and the Department of Epidemiology at the Ministry of Health. The rate of infection with the pandemic strain was calculated by dividing the number of cases with a positive real-time PCR report by the number of the total estimated population according to age group: Number of H1N1 Pandemic Cases according to age group/General Estimated Population (to July 2009) according to age group x $100,000=$ Incidence per 100,000 habitants.

The analysis of the database was done using the Epi-Info Version 3.5.1 (CDC- Atlanta, Georgia,
USA) program. The results were expressed in rates, relative frequencies with their respective percentages.

\section{Results}

A total of 806 subjects with a positive test for 2009 Influenza A (H1N1) pandemic virus were referred to GMI. The incidence in the metropolitan area (Panama City) was 27.08 per 100,000 habitants and in the rest of the country (Provinces) the incidence was 11.66 per 100,000 habitants.

Ninety-nine percent of the subjects who were referred to us had diagnosis of flu-like syndrome and only $1 \%$ reported travelling outside of Panama 30 days before the onset of symptoms. (Table 2). The median age of the patients with a positive result was 13 years with a range between one day to 88 years. The male-to-female ratio was $1: 1$. The proportion of patients who had received the seasonal influenza vaccine before they developed pandemic influenza was $15.9 \%$ in infants younger than two years of age and $5 \%$ in subjects older than 60 years. Other age groups were not vaccinated in the country. The overall incidence of pandemic cases was 23.35 per 100,000 habitants (Table 3). A greater proportion of infection with pandemic 2009 Influenza A (H1N1) 
Table 3. Age distribution of the number of cases and incident rate for patients with pandemic 2009 influenza A (H1N1)

\begin{tabular}{|l|l|l|l|}
\hline Age range (years) & Number of cases & $\begin{array}{l}\text { Total estimated } \\
\text { population by age }\end{array}$ & $\begin{array}{l}\text { Incidence rate by age } \\
\text { group (per 100,000 } \\
\text { cases) }\end{array}$ \\
\hline$\leq \mathbf{1}$ & & & \\
\hline $\mathbf{1 - 4}$ & 25 & 141,026 & 17.72 \\
\hline $\mathbf{5 - 9}$ & 85 & 209,505 & 40.57 \\
\hline $\mathbf{1 0 - 1 4}$ & 134 & 339,697 & 39.44 \\
\hline $\mathbf{1 5 - 1 9}$ & 191 & 325,520 & 58.67 \\
\hline $\mathbf{2 0 - 2 4}$ & 86 & 305,562 & 28.14 \\
\hline $\mathbf{2 5 - 3 4}$ & & & 17.26 \\
\hline $\mathbf{3 5 - 4 9}$ & 51 & 295,474 & 16.57 \\
\hline $\mathbf{5 0 - 5 9}$ & 89 & & 13.16 \\
\hline $\mathbf{6 0 - 6 4}$ & 90 & 536,968 & 12.12 \\
\hline$\geq \mathbf{6 5}$ & 35 & 683,695 & 4.85 \\
\hline TOTAL & 5 & 288,802 & 6.78 \\
\hline Source: Data base from the Gorgas Memorial Institute & 103,017 & 23.35 \\
\hline
\end{tabular}

among those with acute respiratory illness was detected in the age group between 10 to 14 years with 58.67 cases per 100,000 habitants, followed by subjects between 1 to 4 years with 39.44 cases per 100,000 habitants. More than half of the cases were between the ages of one and 14 years. Most of the cases occurred between the epidemiological weeks 18 (the first case was detected on 8 May 8 2009) and 38 with subsequent significant reduction in the number of cases. Eighty-nine percent of the patients were treated as outpatients; the case fatality rate was $1.3 \%$.

\section{Discussion}

This investigation provides a better understanding of the epidemiological profile of the pandemic 2009 Influenza A (H1N1) in Panama. The low morbidity and mortality of the pandemic 2009 Influenza A (H1N1) cases in Panama seems to contrast with the severity reported in countries such as Mexico, Colombia, and Argentina [6-8]. The fast identification of the cases, the easy access to health services, and a warm climate that could affect a thermo-labile virus could be some of the factors that would explain the differences in clinical picture. Children and adolescents were the age group with the highest incidence. This finding may suggest the need to consider vaccination in children older than 2 years.
2009 Influenza A (H1N1) was uncommon in the age group older than 60 years. A recent publication [8], suggests that the stimulation of antibody by prior exposure through infection or vaccination to influenza virus genetically and antigenically related to pandemic 2009 Influenza A (H1N1) would confer immunity or partial protection; however, in our population, a low percentage of subjects in this age group were vaccinated, which would not allow us to conclude that as a relevant scientific finding. This it is the first overview of the behavior of the illness by 2009 Influenza A (H1N1) in Panama. It establishes the baseline for understanding the epidemiological aspects and prepares us in the event that the country faces a second wave with a subsequent change in the epidemiological profile.

\section{Acknowledgments}

We thank the US Health and Human Services for the unlimited support provided for the purchase of supplies and reagents during the 2009 Influenza A (H1N1) pandemic in Panama that allowed the generation of the data presented here. We are also grateful to the Virology and Genomics group at GMI and the Ministry of Health in Panama.

\section{References}

1. Lessler J, Reich NG, Cummings DA; New York City Department of Health and Mental Hygiene Swine Influenza Investigation Team, Nair HP, Jordan HT, Thompson N. Nair HP, Jordan HT, Thompson N, et al. (2009) Outbreak of 
2009 pandemic influenza A (H1N1) at a New York City school. N Engl J Med 361: 2628-2636.

2. Dawood FS, Jain S, Finelli L, Shaw MW, Lindstrom S, Garten RJ, Gubareva LV, Xu X, Bridges CB, Uyeki TM (2009) Emergence of a novel swine-origin influenza A (H1N1) virus in humans. N Engl J Med 360: 2605-2615.

3. Perez-Padilla R, de la Rosa-Zamboni D, Ponce de Leon S, Hernandez M, Quiñones-Falconi F, Bautista E, RamirezVenegas A, Rojas-Serrano J, Ormsby CE, Corrales A, Higuera A, Mondragon E, Cordova-Villalobos JA; INER Working Group on Influenza: Rodriguez J, Barrales M, Reveles L, Sanchez-Mecatl MA, Ibarra D, Leon LE, Gutierrez T, Rodriguez-Parga D, Aguilar C, Rocha F, Serna I, Huizar V, Castañeda B, Garcia JG, Sandoval JL, Hernandez R, Flores F, Amaya L, Espinoza C, Sada E, Reyes-Teran G, Romo J, Osorio A, Sevilla E, Alejandre A, Rodriguez-Filigrana S, Chavarria J, Fernandez R, GarciaSancho C, Franco F, Alfaro-Ramos L, Godinez-Zavala J, Martinez L, Damian L, Garcia-Torrentera R, Sotelo R, Alba LF, Vazquez ME, Peña E, Selman-Lama M, Manjarrez ME, Zuñiga J, Diaz A, Mora C, Fernandez F, de Jesus Contreras F, Villaloz JP, Romero S (2009) Pneumonia and respiratory failure from swine-origin influenza A (H1N1) in Mexico. N Engl J Med, 361: 680-689.

4. CDC protocol of realtime RTPCR for Influenza A(H1N1). Geneva: World Health Organization, April 2009. http://www.who.int/csr/resources/publications/swineflu/realt imeptpcr/en/index.html

5. Frank AL, Couch RB, Griffis CA, Baxter BD (1979) Comparison of different tissue cultures for isolation and quantitation of influenza and parainfluenza viruses. J Clin Microbiol 10: 32-36.

6. Libster R, Bugna J, Coviello S, Hijano DR, Dunaiewsky M, Reynoso N, Cavalieri ML, Guglielmo MC, Areso MS, Gilligan T, Santucho F, Cabral G, Gregorio GL, Moreno R, Lutz MI, Panigasi AL, Saligari L, Caballero MT, Egües
Almeida RM, Gutierrez Meyer ME, Neder MD, Davenport MC, Del Valle MP, Santidrian VS, Mosca G, Garcia Domínguez M, Alvarez L, Landa P, Pota A, Boloñati N, Dalamon R, Sanchez Mercol VI, Espinoza M, Peuchot JC, Karolinski A, Bruno M, Borsa A, Ferrero F, Bonina A, Ramonet M, Albano LC, Luedicke N, Alterman E, Savy V, Baumeister E, Chappell JD, Edwards KM, Melendi GA, Polack FP (2010) Pediatric hospitalizations associated with 2009 pandemic influenza A (H1N1) in Argentina. N Engl J Med 362: p 45-55.

7. Rey-Benito GJ, Castro- Jiménez, MA Castillo-Pabón JO (2009) Influenza A H1N1. Análisis descriptivo de las primeras muertes por influenza pandémica. Infectio 13: 254-258.

8. Garcia-Garcia L, Garcia-Garcia L, Valdespino-Gómez JL, Lazcano-Ponce E, Jimenez-Corona A, Higuera-Iglesias A, Cruz-Hervert P, Cano-Arellano B, Garcia-Anaya A, Ferreira-Guerrero E, Baez-Saldaña R, Ferreyra-Reyes L, Ponce-de-León-Rosales S, Alpuche-Aranda C, RodriguezLópez MH, Perez-Padilla R, Hernandez-Avila M (2009) Partial protection of seasonal trivalent inactivated vaccine against novel pandemic influenza A/H1N1 2009: casecontrol study in Mexico City. BMJ 339: b3928.

\section{Corresponding author}

Nieto-Guevara, Javier

Instituto Conmemorativo Gorgas de Estudios de la Salud

Ave. Justo Arosemena y Calle 35

PO Box: 0816-02593

Panama, Rep. de Panama

Telephones: (507) 527-4800, (507) 66186048

Fax: (507) 527-4889

Email: nietdom@gmail.com

Conflict of interests: No conflict of interests is declared. 